\title{
Correction: Dual role for miR-34a in the control of early progenitor proliferation and commitment in the mammary gland and in breast cancer
}

\author{
Paola Bonetti $\mathbb{1}^{1} \cdot$ Montserrat Climent $^{1} \cdot$ Fabiana Panebianco $^{1} \cdot$ Chiara Tordonato $^{2} \cdot$ Angela Santoro $^{3}$. \\ Matteo Jacopo Marzi ${ }^{1} \cdot$ Pier Giuseppe Pelicci ${ }^{3,4} \cdot$ Andrea Ventura $^{5} \cdot$ Francesco Nicassio $^{1}{ }^{1}$
}

Published online: 8 November 2019

(c) The Author(s) 2019. This article is published with open access

\section{Correction to: Oncogene}

https://doi.org/10.1038/s41388-018-0445-3

The original version of this Article contained errors in the author affiliations.

Affiliation number 3 incorrectly read 'Department of Experimental Oncology, European Institute of Oncology (IEO), 20100 Milan, Italy'. It should read 'IEO, European Institute of Oncology IRCCS, Department of Experimental Oncology, Via Adamello 16, 20139 Milan, Italy'. Affiliation number 4 incorrectly read 'Dipartimento di Scienze della Salute, Università degli Studi di Milano, 20100 Milan, Italy'. It should read 'Department of Oncology and Hemato-
Oncology, University of Milan, Via Santa Sofia 9, 20142 Milan, Italy'.

Open Access This article is licensed under a Creative Commons Attribution 4.0 International License, which permits use, sharing, adaptation, distribution and reproduction in any medium or format, as long as you give appropriate credit to the original author(s) and the source, provide a link to the Creative Commons license, and indicate if changes were made. The images or other third party material in this article are included in the article's Creative Commons license, unless indicated otherwise in a credit line to the material. If material is not included in the article's Creative Commons license and your intended use is not permitted by statutory regulation or exceeds the permitted use, you will need to obtain permission directly from the copyright holder. To view a copy of this license, visit http://creativecommons. org/licenses/by/4.0/.

The original article can be found online at https://doi.org/10.1038/ s41388-018-0445-3.

Paola Bonetti

paola.bonetti@iit.it

$\bowtie$ Francesco Nicassio

francesco.nicassio@iit.it

1 Center for Genomic Science of IIT@SEMM, Istituto Italiano di Tecnologia (IIT), 20139 Milan, Italy

2 IFOM, The FIRC Institute for Molecular Oncology Foundation, 20139 Milan, Italy

3 IEO, European Institute of Oncology IRCCS, Department of Experimental Oncology, Via Adamello 16, 20139 Milan, Italy

4 Dipartimento di Scienze della Salute, Università degli Studi di Milano, 20100 Milan, Italy

5 Memorial Sloan-Kettering Cancer Center (MSKCC), New York, NY, USA 